\title{
Intelligent automated public transportation systems with enhanced security
}

\author{
K. Sivakumar \\ Asst. Professor, Department of Electronics and Communication Engineering, Rajalakshmi Institute of \\ Technology, Chennai, India. \\ sivakumar.k@ritchennai.edu.in
}

\begin{abstract}
A significant population of our country are folks with an average income who depend on public transportation to go about. But this method of transport has become one of the most chaotic and also has a high percentage of crime sites for numerous incidents. Hence this method has the most insecure position for the public and also a pollution generating state. Out of the full population of India as per 2017, around 5.5 percent of the total GDP go by road dependent on the public transit. The aim of this work is develop Smart automatic Public transport System with improved security to provide convenience to passengers who are unaware of the complete information about the buses such as availability of seats, journey time, distance travelled and to make sure they experience the same comfort as their personal vehicles.
\end{abstract}

Keywords : Transport systems, Smart automatic system, security.

\section{INTRODUCTION}

The country's pollution bureau claims that traffic congestion and noise pollution had grown by 3.2 percent as of the time of this report. Daily, about $8.5 \%$ of the country's passenger flow is carried by public busses. It has been noticed that the percentage of travel done by road has declined from $7.2 \%$ of the GDP to 5.5\% of the GDP in our nation [38]. This is because of the inefficient administration of the busses, which has led to increased pollution in the roadways.Besides this, individuals have unlawfully entered the buses, making many criminal scenes. Additionally, many have stopped using public transportation due to this. A government collapsed into the river because so many people weighed it down. The buses skewed towards one side because passengers leaned heavily on the bus entryway. This catastrophe cost the lives of around 37 individuals who were aboard the bus. James J. Barry, Robert Newhouser, Adam Rahbee, and shermeenSayeda, in the year 2002, developed the city's automated fare collecting system, called the Metro Card, for New York City Transit. Two key assumptions guide the algorithms. First, it is common for many riders to begin their next journey by returning to the prior stop on their route.

Additionally, close to half of the people who complete their last journey of the day return to the station where they started their first ride of the day. It was deduced from this diary information that both hypotheses are accurate for $90 \%$ of metro riders. The results were then confirmed by examining inferred destination totals vs station exit counts at different times of day, and by applying a trip assignment model to estimate peak load point passenger numbers. The primary uses of this project are to produce O-D trip tables as input to a trip assignment model, and to document travel patterns for service planning. Using this approach, O-D surveys no longer have to be performed on a regular basis.In 2007, M.Parent invented the vehicle that was significant in shaping the course of urban growth during the 20th century, and which is today important to urban (suburban) operations. To address the 21st century's problems, we must now think of a new kind of urban mobility. There is a hierarchy in this transport system, with high-capacity linkages at the top, medium- and low-capacity links in the middle, and demand control and optimization at the lower layers. It is the goal of the service to provide door-to-door transportation for anybody or anything at any time, however the fees will change based on the means of transportation employed.In 2008, 13 people in Saao Paulo, Brazil, collaborated to create an origin-destination matrix (ODM) from 
data gathered through automated data collection (ADC) devices. Previously, researchers investigated developing ODMs utilizing ADC systems; however, the Saao Paulo example is significantly different. This article focuses on a more complicated bus network than other papers have previously. Data sources used throughout the ODM development process include bus stops, vehicle position data, and fare collecting system data. Analysis and comparison of the electronically generated ODM findings are performed.In the year 2011, Wei Wang, John P. Attanucci, and Nigel H. M. Wilson [31] created an Automated Data Collection Systems (ADCS) that enabled the automatic collection of travel behavior information for bus passengers, such as the determination of ODCs, with London serving as a case study.

This shows that trip chaining may be applied to detect bus passenger on-board data using automatic vehicle location (AVL) and smart card transactions, and it is the first known attempt to verify trip chaining's results by comparing them to manual passenger data. Alighting times for bus passengers are also calculated, based on the inferred OD matrices and the AVL data. It gives a method to compare connections on buses and bus routes; with this, we can measure how long it takes to get from one place to another.In 2014, Arun Das.S and K. Lingeswaran invented a GPS-based public transport fare collection system for automated passenger transport that use a smart card. The goal of this article is to make travelling a stress-free and easy experience, as well as to decrease the amount of manpower required. The use of smart cards and GPS makes travelling smarter in this study. The user can use this smart card to board and exit the bus. Cardholder funds will be taken from the money that has been paid in advance depending on how far one has traveled. The entire system is controlled by the microcontroller that this paper implements. GPS and smartcard work with it really well.

In the year 2014, Marcela Munizaga, FlavioDevillaine, Claudio Navarrete, and Diego Silva used a validation of public transportation origin-destination (OD) matrices that were collected using smartcards and GPS data to assess the validity of the public transport matrix formulas. Valuable matrices for management and planning have only just recently been verified. Using the same database used to calculate the estimations, a Metro OD survey in which the card numbers are registered for a group of users, and a sample of volunteers, here demonstrate the assumptions and outcomes of the technique. With a success rate of around 90\%, the outcomes were all good.Himanshu Sharma, Parvesh Mor, and Ankur Sodhi, in the year 2014, developed a Smart Transportation Management System They implemented the system using two-way communication.RFID encryption mechanism This study demonstrates a transport management system that is intelligent. The project included RFID technology into the construction of a transport management system (TMS) that was loaded into the host computer. On the other hand, an intelligent transport management system (ITMS) manages transport tasks while maintaining security and integration. A two-way encryption method is employed to secure the information. The transport management system capability is explained using a software program in Microsoft Visual Basic.Net.

GIS method coupled with RFID and GPS technology provided a reliable and safe bus ticketing system that was realized in 2015 by T.Manikandan, G.Kalaiyarasi, K.Priyadharshini, and R.Priyanga. The project's aim is to count the number of passengers using an IR sensor and calculate the distance they've traveled using a motor and u-slot sensor, and the amount debited from the RFID card is the same as the revenue. In addition, information on any incident is instantly relayed to the nearest hospital utilizing GSM and GPS in proposed system. Here, the RFID tag is rechargeable, while in a bus terminal or a nearby retail establishment, it may be recharged. micro-controlled, keypad and LCD are included for recharging at the bus depot as an additional feature.In 2017, B.Vamsi Krishna, under the helm of Design and Development of Automated Public Transportation System and Traffic Guidance System, developed the whole public transportation system and traffic guidance system. It solves the majority of these difficulties by combining existing technologies with the infrastructure. The discussion here revolves around the usage of GPS and Android together, which can meet the transportation needs of those who commute by public transit. This implementation uses Android bus APP and user APP to minimize the cost and size of hardware while producing a better result.A mobile ticketing system for automatic fare collecting was 
created by Yemula Prashanth Reddy and P.Satish in 2017. This article uses the commuter's Cell phone as a cell phone.

The Mobile Ticketing model comprises of a registered mobile subscription, either prepaid or postpaid, for the identity of the traveler. This subscription can be obtained through scanning the phone number of the traveler's mobile phone before or after they enter or exit a vehicle or station, or even when riding as a passenger. After that, the phone number and fare are deducted, and the information is sent to the service provider of the Mobile connection.In 2017, [24] Sunitha, Sangeetha, and Vidhyajanani designed an Automatic Fare Collection System that used RFID Smart cards to carry out the work. In order to enter the bus, each passenger receives an RFID card, which is then swiped in an RFID reader before boarding. Once on board, the card is used to access a device that automatically calculates the fee and collects the money. People don't have to pay if they don't want to, because the conductor feels free to collect the money from the people. The server is in continuous communication with the records;thus all the information is always up to date. A smart web website is able to keep track of how far a bus travels, how many passengers are on the bus, and how much path it takes.It was determined after taking all of the previous conversations into consideration regarding the usage of GPS and RFID which is widely used has the difficulties of occasional or missing tracking of position in distant locations and inaccurate frequencies. Our concept calls on us to build an android application to avoid the issues.

\section{PROPOSED WORK}

The current technology helps to find which free seats are available on the bus, and where the bus is at any given moment using mobile phone network position. Passengers may be able to enter their destination via the app, which then allows the app to access the information. That traveler is therefore able to reserve a seat on the next bus that will take him to his final destination. QR codes will be created based on the reservation and will act as boarding passes to board the bus, as well as the seats assigned to the reservation. Every time RSU controller sends information to the ARM Cortex M4 controller, ESP8266 updates the information (Wi Fi module).The chart in Figure 1 illustrates the general module layout, which has three calls: confirmation, update, and login. A passenger sends the login request to the online cloud, and this is forwarded to the admin hub as confirmation. Finally, the confirmation is provided to the passenger, and the update signal is transmitted to the cloud. The user has access to the booking services after he inputs the user ID and password. The time, distance, and availability of seats are shown with relation to the time and distance database and seat calculation database after inputting the starting point and destination. In the end, the user chooses whether to submit or cancel. A coupon is created if 'submit' is selected, and the coupon is utilized for the bus ticket confirmation. If there is conflict between the number printed on the coupon and the number submitted, the ticket will not be confirmed. A detailed diagram of the flow of functions is depicted in fig. 2 .

\section{A. Hardware Description - ARM Cortex-M4 Processor}

The ARM Cortex-M4 processor is a high-performance embedded processor with DSP instructions developed to address digital signal control markets that demand an efficient, easy-to-use blend of control and signal processing capabilities. The processor is highly configurable enabling a wide range of implementations from those requiring floating point operations, memory protection and powerful trace technology to cost sensitive devices requiring minimal area.

\section{B. Wi Fi Module}

The ESP8266 Wi fi Module is a self-contained SOC with integrated TCP/IP protocol stack that can give any microcontroller access to userWifi network. It is capable of either hosting an application or offloading 
all Wi-Fi networking functions from another application processor. Each ESP8266 module comes preprogrammed with an AT command set firmware, meaning, one can simply hook this up touser's controller device and get about as much Wifi-ability as a Wifi Shield offers. The ESP8266 module is an extremely cost-effective board with a huge, and ever growing, community.

\section{Hardware Applications}

The Cortex-M4 has been specifically developed for partners to design high performance low-cost devices for a broad range of digital signal control embedded market segments including automotive control systems, Building automation, Domestic household appliances, Energy grid and many.

\section{Result and discussion}

In this work MIT application invertor software (version 2) is used. The project results are viewed in the Energia GUI window.Figure 2 shows the bus ticketing login screen to the user. In Fig. 4.1, the output is obtained in the form of application the passenger's smart phones.

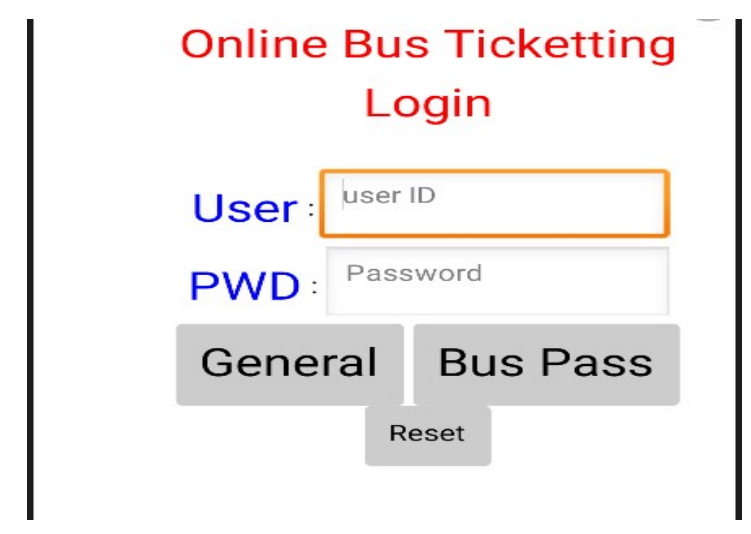

Fig. 1 Login Screen

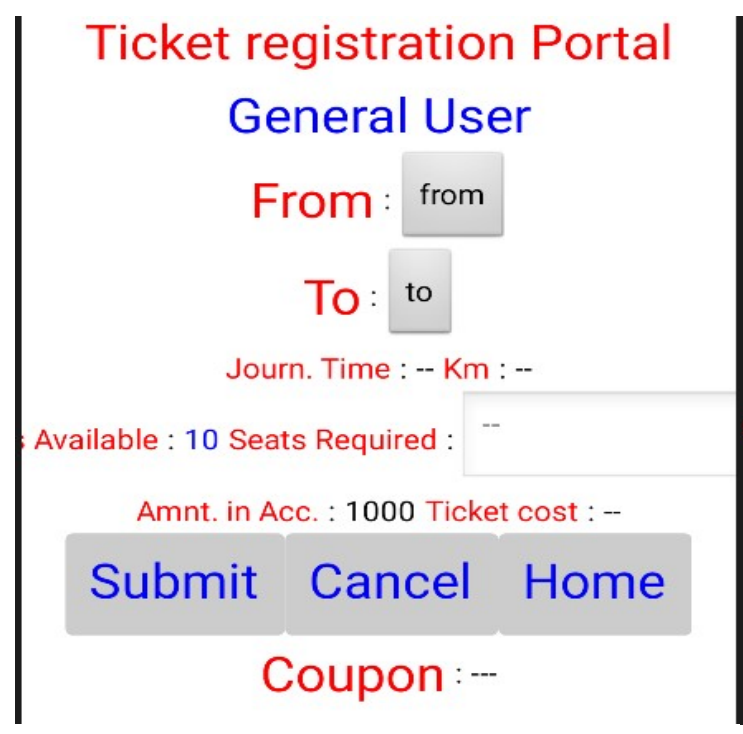

Fig. 2(a) Registration Portal 1

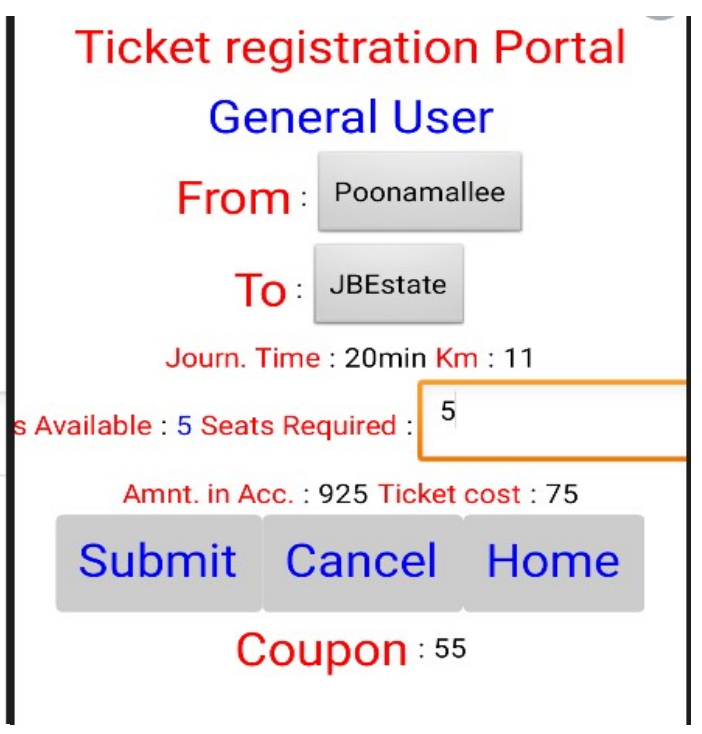

Fig. 2(b) Registration Portal 2 


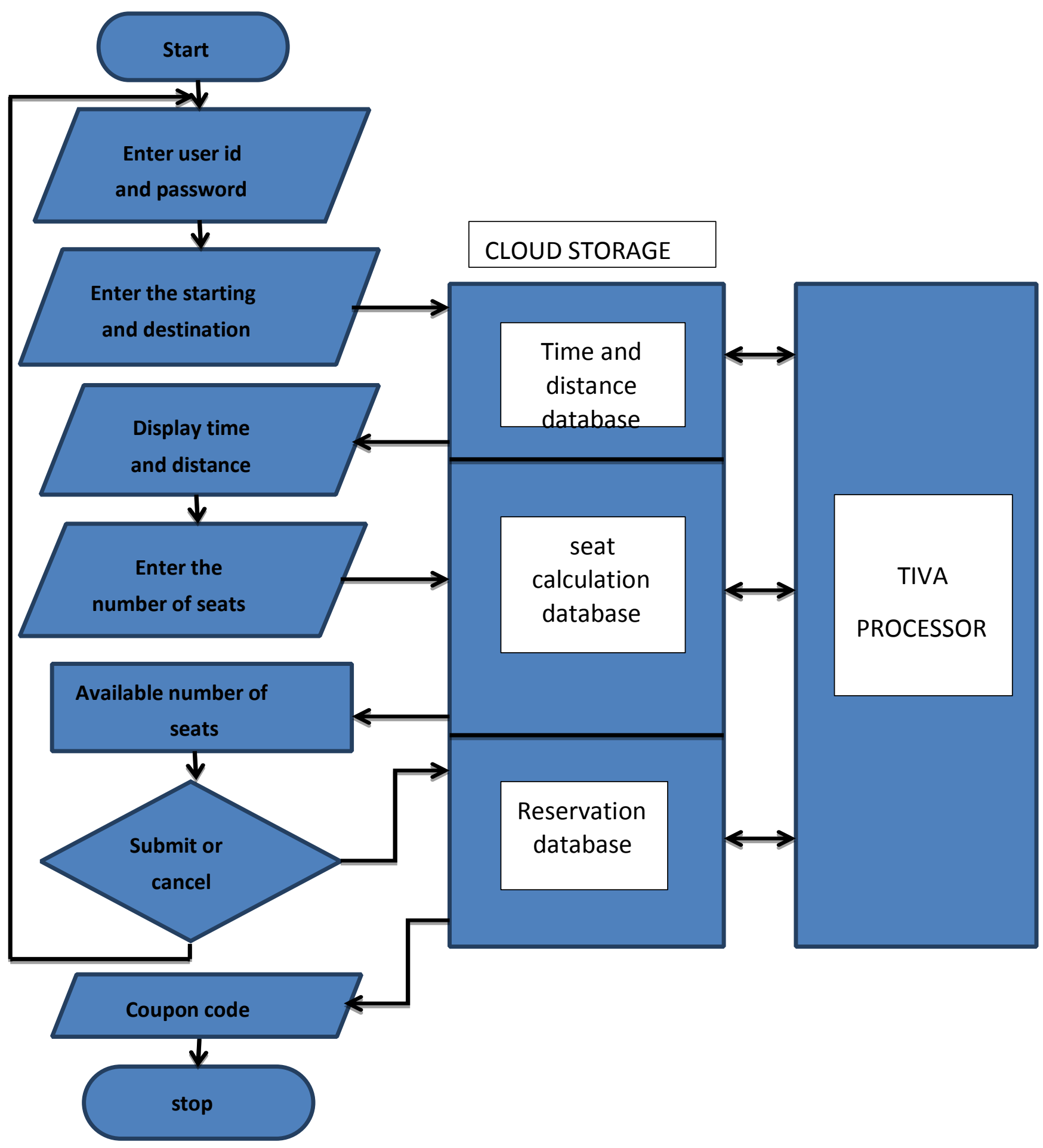

Fig. 3 The flow chart of the proposed method 
The mobile app login page includes a User ID and a Password. Once the user has provided their user ID and password, the user must then pick between general and bus pass categories. The user must provide the beginning position and the destination point in order to register. In order to ease the calculation of the user's trip, after it is input, the calculator automatically calculates the kilometer and the journey time. in Fig. 2 below (b). The code that is produced once the booking is verified will be used to board the bus for authentication purposes. The flow chart of the proposed method is shown in figure 3.

\section{c. Energia Code Segment}

The code is loaded into the energia code window and is compiled and uploaded to the hardware processor. The overall setup of the energia code segment is shown above in Fig. 3. The lower space in the window denotes the compiler segment, which denotes the errors and warnings that arise in the program during compilation. Fig. 4 Code Setup in EnergiaWindow .

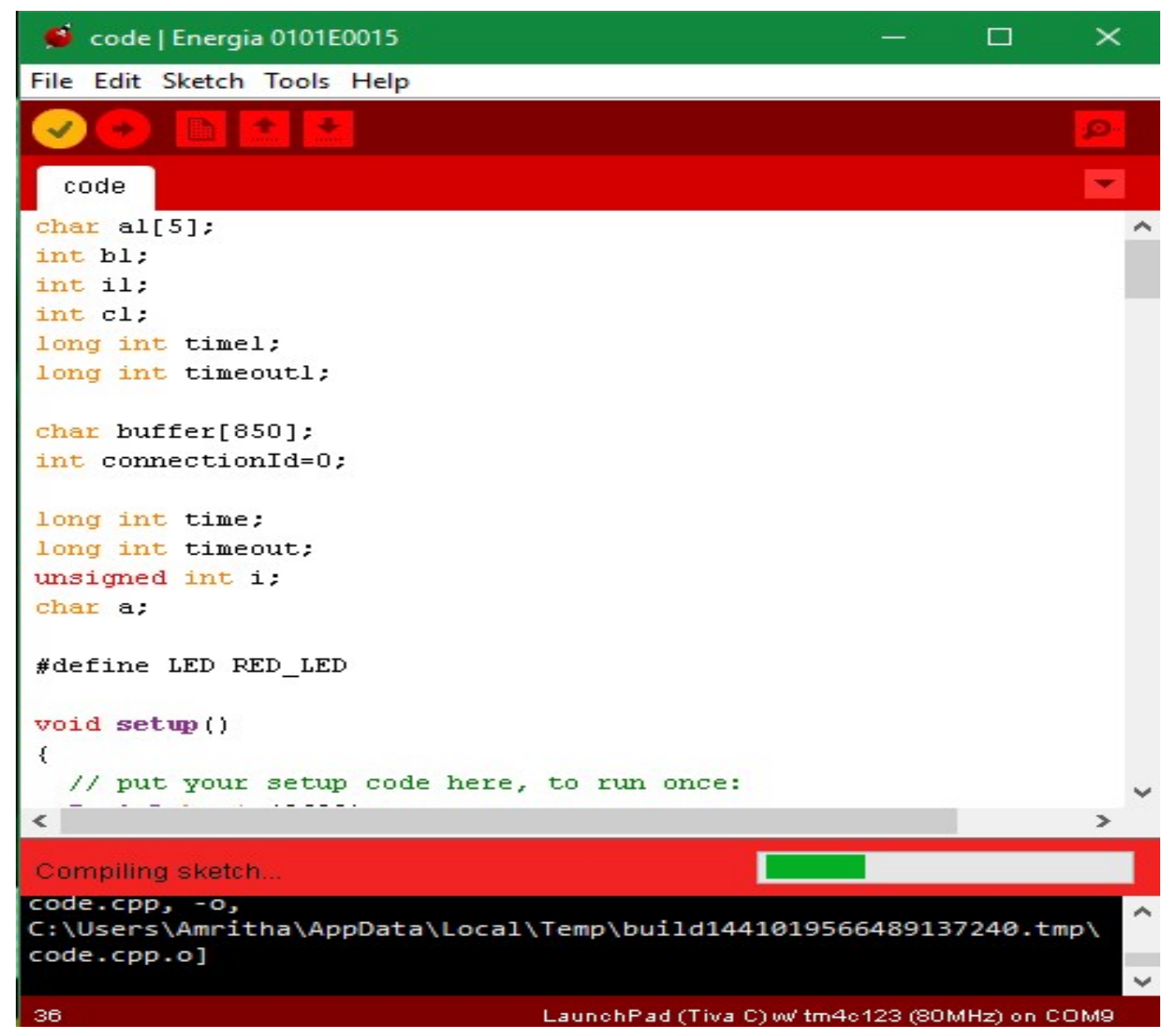

Fig. 4 Code Setup in Energia Window

The MIT application site is divided into four sections: the palette, the viewer, the components, and the properties. The palette contains user interface components like as buttons, checkboxes, and a data picker, among others. The viewer portion contains the primary workspace where the mobile application's main layout is built for the user's perspective. The components section contains the different code snippets for the viewer section's parts. The properties section, located in the window's bottom right corner, provides extra alignment features for the newly formed application. This work is divided into four pieces, as seen in Fig. 5. The block pane contains the produced code in block format. Each block is a pre-defined function from the MIT App Invertor's library. The code's block format is seen in Figure 6. The code blocks are created and then assembled and stored to represent the data to the users in the form of an 
application.The program's output is shown in the serial monitor, which is the output window in the energia software, when the user enters the right code produced in the appropriate application on their smart phone.

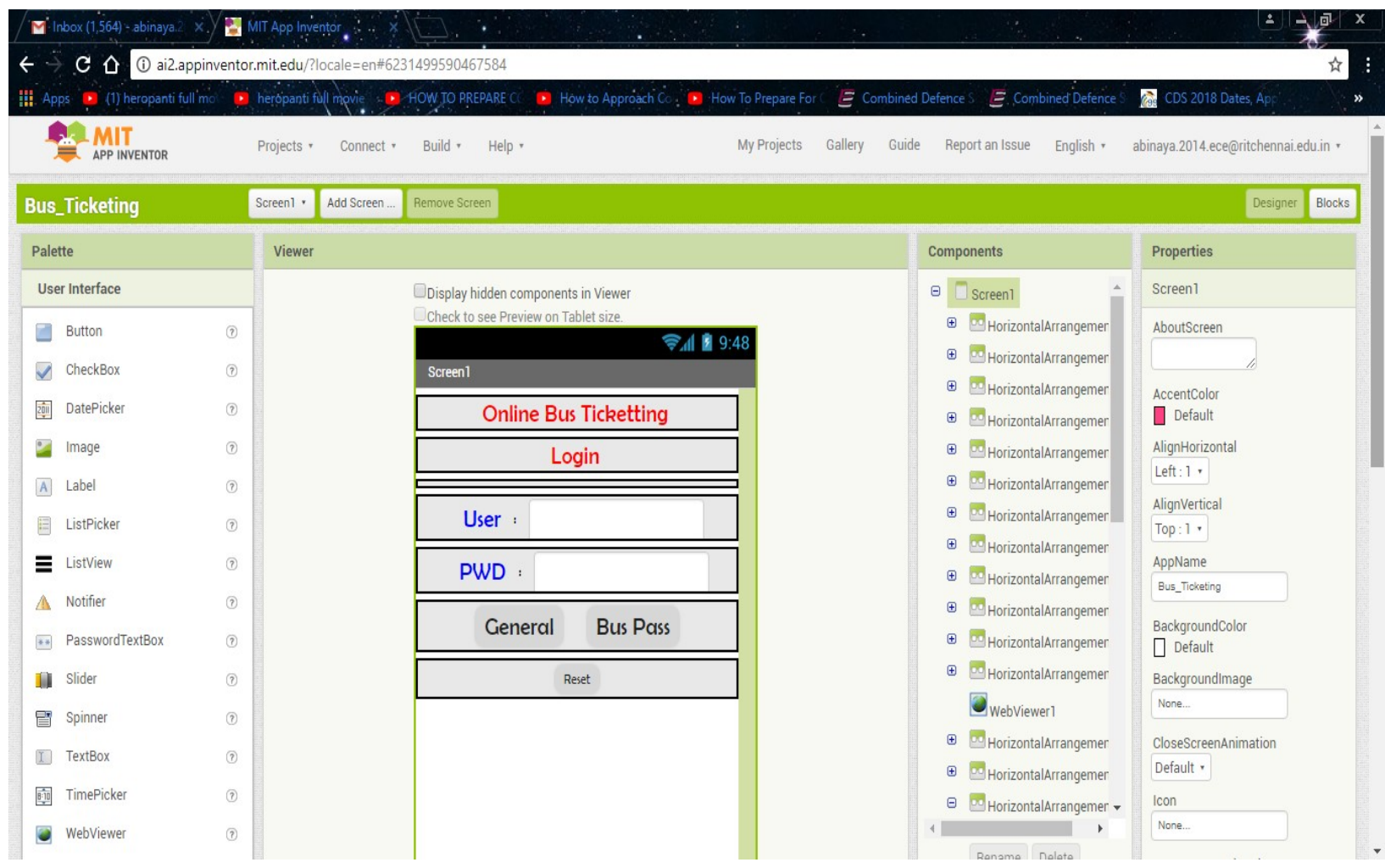

Fig. 5 MIT Login Page Layout

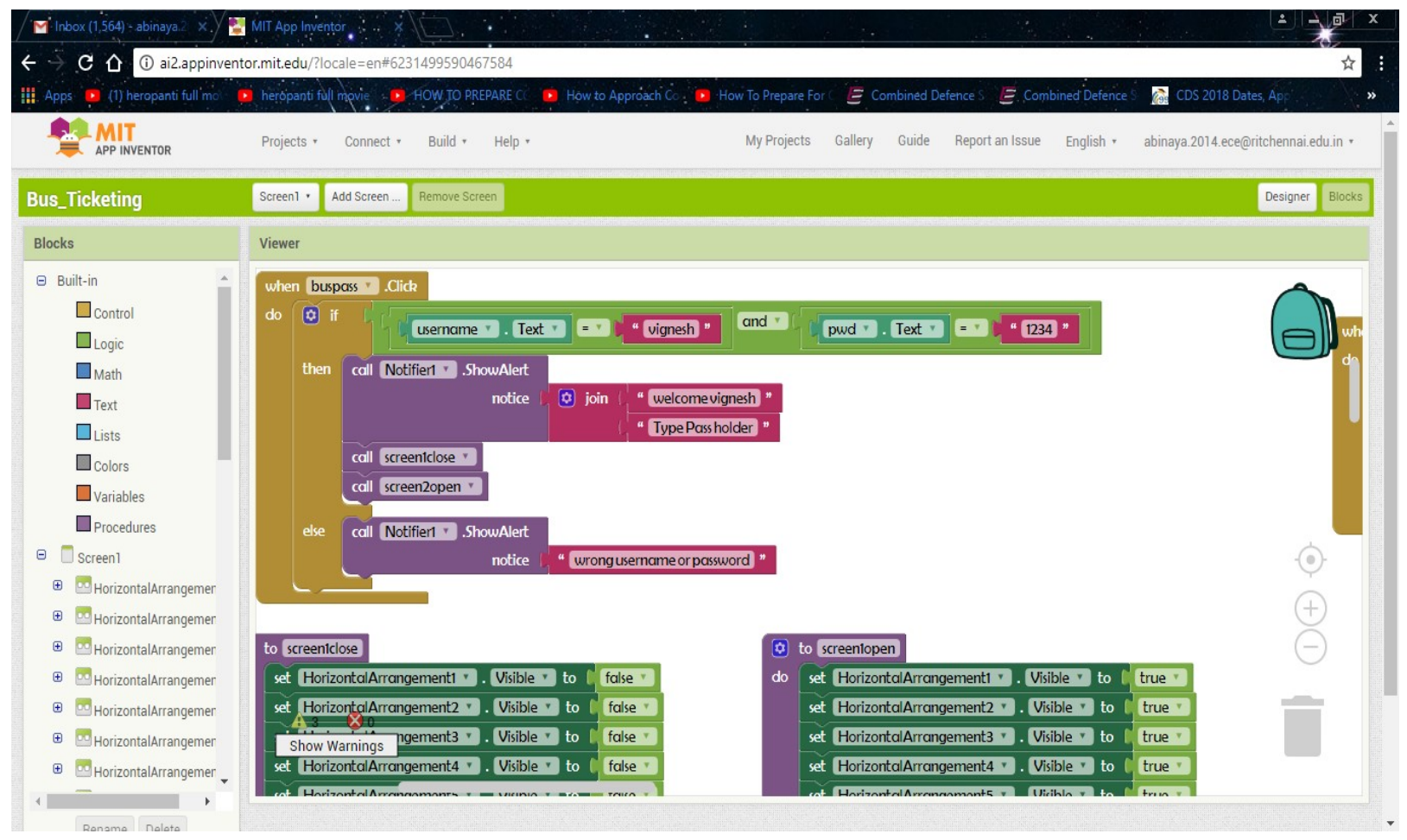

Fig. 6 MIT Application Block Segment 


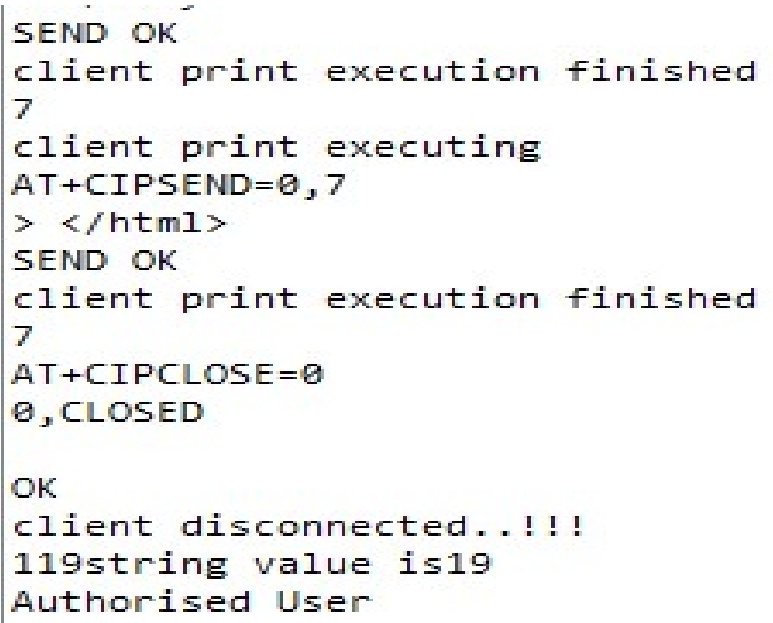

Fig. 7 Serial Monitor Output

In case of misuse or mismatching of the coupon code, the serial monitor displays the output as unauthorized user and the confirmation of the ticket will not be done

\section{CONCLUSION AND FUTURE WORK}

Due to its cost effectiveness and adaptability, an automated public transportation system is an appealing urban transit solution in this study. However, it appears that introducing automated public transportation systems in cities will be difficult, as the majority of city structures have been developed solely for road transport development, and the lack of land use control has resulted in a slew of problems, including urban sprawl, traffic congestion, and air pollution. This article will discuss many ways for promoting automated public transit in Asian emerging cities. In the future, one can aid criminal department investigations by including the aadhar card scan verification stage into the application login process. By adding this and gaining authorization from the government for database access, we may access the public's fingerprints associated with the QR code on each aadhar card. We can conduct investigations into different criminal cases that have been stalled by the judicial system using data collected from the government-secured database. This additional layer of security may be added by including the following features: (i) Including a scan reader code snippet in the application to scan the QR code from the aadhar card. (ii) Obtaining government authorization to access the database.

\section{REFERENCE}

[1] Arun Das .S and K. Lingeswaran, March (2014), "GPS based Automated Public Transport Fare Collection Systems Based on Distance Travelled by Passenger Using Smart Card”, International Journal of Scientific Engineering and Research (IJSER), ISSN: 2347-3878 Volume 2 Issue3.

[2] Bagchi, M., and White, P.R., (2005). The potential of public transport smart card data Transport Policy, Volume 12 (5), pp. 464-474.

[3] Barry, J.J., Newhouser, R., Rahbee, A., Sayeda, S., (2002). Origin and destination estimation in New York City with automated fare system data. Transportation Research Record 1817, pp. 183-187.

[4] Barry, J., Freiner, R. and Slavin, H., (2009). Use of entry-only automatic fare collection data to estimate linked transit trips in New York City. Transportation Research Record 2112, pp. 53-61. 
[5] Bo Yan, Danyu Lee, (2009), "Design of sight spot ticket management system based on RFID”, International Conference on Automation.

[6] Devillaine, F., Munizaga, M.A. and Trepanier, M., (2012). Detection activities of public transport users by analyzing smart card data. Transportation Research Record 2276, pp. 48-55.

[7] Devillaine, F., Munizaga, M.A., Palma, C. and Zúñiga, M., (2013), “Towards a reliable OriginDestination matrix from massive amounts of Smartcard and GPS data”, Transport Survey Methods; Best Practice for Decision Making, Emerald, pp. 695-710.

[8] Dr.S.Krishna Murthy and Mr. A.Nagabhushan Rau, January (2006), "Management of construction equipment”, Journal of All India Council for Technical Education, Volume-19, pp.19- 32.

[9] Farzin, J., (2008). Constructing an automated bus Origin-Destination matrix using farecard and global positioning system data in Sao Paulo, Brazil. Transportation Research Record 2072, pp. 30-37.

[10] Hongqin Fan, Hyoungkwan Kim, and Osmar R. Zaiane, March (2006), "Data Warehousing for Construction Equipment Management”, Canadian Journal of Civil Engineering, vol-33, pp.1480-1489.

[11] James J.Barry, Robert Newhouser, Adam Rahbee and shermeenSayeda, January (2002), "Origin and Destination Estimation in New York City with Automated Fare System Data", article in Transportation Research Record Journal of the Transportation Research Board 1817(1817): pp.183-187.

[12] Janine M.Farzin, December (2008), “Constructing an Automated Bus Origin-Destination Matrix Using Farecard and Global Positioning System Data in São Paulo, Brazil”, Article in Transportation Research Record Journal of the Transportation Research Board 2072(2072), pp. 30-37

[13] Lianfu, Z., Shuzhi, Z., Yonggang, Z., Ziyin, Z., (2007). Study on the method of constructing bus stops OD matrix based on IC card data. Wireless Communications, Networking and Mobile Computing WiCom 2007, pp. 3147-3150.

[14] Marcela Munizaga, FlavioDevillaine, Claudio Navarrete and Diego Silva, July (2014), "Validating travel behavior estimated from smartcard data", published in Transportation Research Part C 44 (2014), pp. 70-79.

[15] Maria Grazia GMONI, et al, (2009), “A smart model for urban ticketing based on RFID applications”, IEEEMO9-p-0572, IEEE.

[16] Mohan D, Tsimhoni O., Sivak M., Flannagan M.J., January (2009), "Road Safety in India: Challenges and Opportunities”, The University of Michigan, Transportation Research Institute, Michigan, U.S.A., pp.1-57.

[17] Munizaga, M.A. and Palma, C., (2012). Estimation of a disaggregate multimodal public transport origin-destination matrix from passive Smart card data from Santiago, Chile. Transportation Research, pp. 9-18.

[18] M.Parent, (2007), “Advanced Urban Transport: Automation” paper published in IEEE Intelligent Systems, Volume: 22, Issue: 2.

[19] Omer Tatari and MiroslawSkibniewski, (2006), "Integrated Agent-Based Construction Equipment Management: Conceptual Design”, Journal of Construction Engineering and Management, vol-12, pp. 231-236.

[20] Osama Moselhi and Adel Alshibani, (2009), “Optimization of Earthmoving Operations”, Journal of Construction Engineering and Management, vol-135, pp. 948-954.

[21] Parvesh Mor, Himanshu Sharma and Ankur Sodhi, August (2014), "Smart Transport Management System Implemented Using Two-Way Encryption Mechanism in RFID”, International Journal of Future Computer and Communication, Vol. 3, No. 4.

[22] Pelletier, M.-P., Trépanier, M., and Morency, C., (2011), "Smart card data use in public transit: A literature review”, Transportation Research Part 19C(4), pp. 557-568. 
[23] Sunitha Nandhini.A, Sangeetha.G and Vidhyajanani.J, March (2017), “Automatic bus fare collection system using RFID ”, International Journal of Advanced Research in Computer Engineering \& Technology (IJARCET) Volume 6, Issue 3, , ISSN: $2278-1323218$.

[24] ThanapunPrasertrungruang and B.H.W. Hadikusumo, (2009), "Modeling the Dynamics of Heavy Equipment Management Practices and Downtime in Large Highway Contractors", Journal of Construction Engineering and Management, vol-135, pp. 939-947.

[25] Treepanier, M., Chapleau, R., and Tranchant, N., (2007), "Individual trip destination estimation in a transit smart card automated fare collection system”, Journal of Intelligent Transportation Systems 11(1), pp. 1-14.

[26] T.Manikandan, G.Kalaiyarasi, K.Priyadharshini, and R.Priyanga, (2015), "Conductor less Bus Ticketing System Using RFID and Accident Information through GPS and GSM”, IJISET International Journal of Innovative Science, Engineering \& Technology, Vol. 2 Issue 9.

[27] Utsunomiya, M., Attanucci, J., Wilson, N., (2006), "Potential uses of transit smart card registration and transaction data to improve transit planning”, Transportation Research Record 1971, pp. 119-126.

[28] Venugopal prasanth, et al, (2009), “Ticketing solutions for Indian Railways using RFID technology”, International conference on advances in computing, control and telecommunication technologies, pp.217-219.

[29] Wang, W., Attanucci, J.P., Wilson, N.H.M., (2011), "Bus passenger origin-destination estimation and related analyses using Automated Data Collection Systems”, Journal of Public Transportation 14 (4), pp. 131150.

[30] Wei Wang, John P.Attanucci and Nigel H.M.Wilson, (2011), "Bus Passenger OriginDestination Estimation and Related Analyses Using Automated Data Collection Systems", published in Journal of Public Transportation 14(4), pp. 131-150.

[31] Yemula Prashanth Reddy, and P.Satish, (2017), "Mobile ticketing system for automatic fare collection model for public transport”, International Journal of Applied Research in Science and Engineering Volume 1, Issue 11.

[32] Zhao, J., Rahbee, A., Wilson, N., (2007), "Estimating a rail passenger trip origin destination matrix using automatic data collection systems”, Computer- Aided Civil and Infrastructure Engineering 22, pp. 376-387.

[33] https://en.wikipedia.org/wiki/Automated_guideway_transit

[34] https://en.wikipedia.org/wiki/Transport_in_India

[35] https://en.wikipedia.org/wiki/Personal_rapid_transit

[36] http://www.facts-about-india.com/transportation-in-India.php

[37] https://economictimes.indiatimes.com/slideshows/infrastructure/9-

recentdevelopments-in-indian-railways/must-see-recent-developments-inindianrailways/slideshow/53351651.cms

[38] https://en.wikipedia.org/wiki/Intelligent_transportation_system

[39] https://en.wikipedia.org/wiki/Automated_parking_system 